\title{
Atitudes de professores e futuros professores em relação à Matemática $^{1}$
}

\author{
Paulo Cézar Faria \\ Universidade Federal do Rio Grande do Norte \\ Maria Lucia Faria Moro \\ Universidade Federal do Paraná \\ Márcia Regina Ferreira de Brito \\ Universidade Estadual de Campinas
}

\begin{abstract}
Resumo
O estudo compara a existência e a direção da atitude em relação à Matemática de quatro grupos amostrais: estudantes de licenciatura em matemática em dois momentos de sua formação, e professores de matemática em dois momentos de exercício profissional. Os dados foram obtidos de participantes voluntários $(N=440)$, por meio de escala de atitude, texto autobiográfico, questionário e entrevista semi-estruturada. A análise estatística dos dados permitiu constatar diferenças na medida de atitudes em relação à Matemática entre os grupos amostrais, sendo significativa a presença de atitude favorável de alunos do início da licenciatura em comparação à de professores em exercício. Essas diferenças foram corroboradas por traços característicos dos tipos de atitude, identificados por análise qualitativa. A mudança de atitude em relação à Matemática pode ser explicada pelas particularidades das diferentes circunstâncias da vida estudantil e profissional. Recomendações para a formação docente em Matemática são sugeridas.
\end{abstract}

Palavras-chave: atitudes; matemática; licenciatura; docência

\begin{abstract}
Attitudes of teachers and future teachers towards Mathematics. This study compares the existence and direction of attitude towards Mathematics shown by four sample groups composed of students enrolled at Mathematics teachers' College in two moments of their training courses, and Mathematics teachers in two moments of their professional life. Data were obtained from volunteer participants $(N=440)$, by means of an attitude scale, an autobiographical text, a questionnaire and a semi-structured interview. The statistical analysis show differences in attitude measurements concerning Mathematics among the sample groups, with a significant presence of favorable attitude in students at the beginning of College when compared to attitudes of practicing teachers. These differences were corroborated by the characteristic traits of attitude types, identified by a qualitative analysis. The attitude change toward Mathematics can be explained by the peculiarities of the different circumstances on the students' and the teachers' lives. Recommendations for teaching training in Mathematics are pointed out.
\end{abstract}

Keywords: attitude; mathematics; graduation; teaching

$\mathrm{U}$ ma primeira investigação sobre o tema da formação de professores de Matemática, desenvolvida em dissertação de mestrado (Faria, 1996), mais resultados obtidos em trabalho de formação continuada com professores de Matemática (Faria, 2003) forneceu os elementos para propor o presente estudo.

O trabalho realizado com os referidos professores revelou indícios de que situações favoráveis ao desenvolvimento de atitudes positivas em relação à Matemática não são freqüentemente vivenciadas na formação inicial do professor nem no exercício da atividade docente. Essa situação acarretaria conseqüências não-satisfatórias à formação inicial, ao exercício da docência e ao desenvolvimento profissional do professor.

Assim, investigar o tema atitude foi considerado, então, interessante, por se entender que essa dimensão deve ser amplamente tratada nos cursos de formação inicial de professores 
de Matemática. Já se tinha a suposição de que atitudes negativas em relação à Matemática, por parte dos estudantes de licenciatura e por parte dos professores em exercício, podem interferir negativamente no ensino da Matemática, trazendo provavelmente conseqüências indesejáveis para a aprendizagem dos alunos dos conteúdos matemáticos na Educação Básica.

A compreensão da natureza das atitudes ocupa lugar de destaque no campo da Psicologia e tem suscitado investigações sistemáticas. Um estudo bastante criterioso a respeito da pesquisa e da teoria que envolve esse conceito foi desenvolvido por Eagly e Chaiken (1993), em que a atitude é compreendida como uma tendência psicológica que é expressa pela avaliação de uma entidade particular, com algum grau de aprovação ou desaprovação. As autoras esclarecem o significado de dois termos utilizados nessa definição. São eles: tendência psicológica, que se refere a um estado interno à pessoa, e avaliação, que se refere a todas as classes de respostas avaliativas (evidentes ou não) de caráter cognitivo, afetivo e conativo. Para as mesmas autoras, o componente cognitivo se refere às idéias ou pensamentos que a pessoa tem sobre o objeto da atitude. O componente afetivo consiste nos sentimentos ou emoções que a pessoa tem em relação ao objeto da atitude e o componente conativo inclui as ações da pessoa com respeito ao referido objeto. Esta é a perspectiva adotada no presente estudo.

Eagly e Chaiken (1993) esclarecem também que as atitudes não podem ser diretamente observáveis, pois se compreende que elas estão relacionadas à predisposição que uma pessoa tem para avaliar um determinado objeto (aprovando-o ou desaprovando-o). Desse modo, as atitudes podem ser inferidas das respostas avaliativas que o participante emite em relação ao objeto da atitude, tendo como suporte os componentes cognitivos, afetivos e conativos.

Portanto, neste estudo, compreende-se que uma atitude se desenvolve a partir de uma resposta avaliativa do participante, ali envolvidos componentes cognitivo, afetivo e conativo. Ao emitir uma resposta avaliativa em relação a qualquer coisa, o participante estaria tendo uma atitude em relação a essa coisa, vista agora como objeto da atitude. Porém, atitude não é diretamente observável, mas é inferida das respostas emitidas pelo participante quando diante do objeto da atitude.

O mesmo ocorreria com as atitudes em relação à Matemática dos professores em formação e dos professores em exercício. Acreditou-se na importância de investigar essa questão com o objetivo de propiciar uma ampliação do conhecimento a respeito do tema da atitude em relação à Matemática e sua importância na formação do professor.

Como declarado acima, a escolha da questão da atitude de professores e futuros professores de matemática se mostrou relevante dada à importância de se abordar a atitude em relação à Matemática como área de conhecimento. Procurou-se verificar se a mudança de atitude em relação à Matemática poderia ser explicada pelas particularidades das diferentes circunstâncias da vida estudantil e profissional.

A conceituação de atitude tem sido objeto de estudo teórico e metodológico no campo da Psicologia, da Sociologia, da Educação e de outras áreas que se dedicam ao estudo do comportamento humano. Ao expressar uma predisposição de significado psicológico e social, ou um sentimento pró ou contra um objeto, a noção de atitude assumiu diversas interpretações e foi alvo de controvérsias. No entanto essas controvérsias foram importantes para um tratamento mais aprofundado do conceito de atitude.

Várias proposições de pesquisadores existem com o intuito de criar modelos que possam fornecer esquemas explicativos e quadros teóricos para os estudos de medida, formação, desenvolvimento e manutenção das atitudes.

Amedida da atitude representa uma parte bastante significativa no estudo científico desse constructo. A possibilidade de inferir a atitude a partir de qualquer expressão de comportamento que reflita um de seus componentes impulsionou os estudos que buscaram a criação de técnicas para a mensuração das atitudes as chamadas escalas de atitudes (e.g., Bogardus, 1925; Guttman, 1944; Likert, 1932; Osgood, Suci, \& Tannenbaum, 1957; Thurstone, 1928). Essas escalas de atitudes são relativamente refinadas e têm sido amplamente utilizadas.

Na conceituação de atitude há que se contemplar seus atributos essenciais e as relações entre eles, para tratar esse constructo de forma adequada. Para tanto foi adotado para o estudo o seguinte enfoque: "atitude poderia ser definida como uma disposição pessoal, idiossincrática, presente em todos os indivíduos, dirigida a objetos, eventos ou pessoas, que assume diferente direção e intensidade de acordo com as experiências do indivíduo” (Brito, 1996, p. 11).

Essa posição de Brito (1996) contém também a idéia de que os três domínios - cognitivo, afetivo e conativo - já aqui abordados, estão presentes no fenômeno da atitude. Dessa forma, essa perspectiva tridimensional é vista pela autora como fundamental para se compreender o lugar das atitudes em relação à Matemática.

O interesse pela compreensão dos efeitos das atitudes dos professores e sua conseqüente repercussão na aprendizagem dos alunos têm provocado o aparecimento de várias pesquisas. Gonçalez e Brito (2001), por exemplo, defendem que professores, com atitudes positivas em relação à Matemática encorajam seus alunos à independência, possibilitando o desenvolvimento do raciocínio e das habilidades básicas para a resolução de problemas. Ao contrário disso, os professores com atitude negativa podem tornar seus alunos dependentes, pois a única fonte de conhecimentos é o professor. Além disso, alguns estudos destacam que a atitude em relação à Matemática tem efeitos significativos sobre o desempenho do aluno, ao longo das séries.

De um modo geral, a busca de compreensão a respeito da influência do professor na geração de atitude negativa (acerca da Matemática) se enquadra dentro de um conjunto de estudos que se referem às suas crenças, atitudes, valores, concepções, ansiedade, percepções, expectativas e tipo de relação que este mantém com o aluno, seja diretamente, ou por meio da metodologia de ensino adotada (e.g., Aiken \& Dreger, 1961; Brito, 1996; García, 1999; Giordano, 1991; Guskey, 1986; Karp, 1991; Larson, 1983; Sallán, 1990; Trillo, 2000). Os resultados dessas pesquisas destacam também que a atitude negativa em relação à Matemática (presente na atividade docente) contribui negativamente para o processo de aprendizagem dos alunos, 
gerando nestes últimos atitudes de perplexidade, desgosto e desespero em relação às situações didáticas em que estão envolvidos.

A compreensão de que as atitudes não são estáveis e, muito menos, cristalizadas, pressupõe naturalmente que o currículo dos cursos de formação de professores de Matemática deva ser estruturado com base em diferentes possibilidades de apreensão de conhecimentos; no sentido de promover o desenvolvimento de uma atitude positiva em relação à Matemática.

Entretanto, há sinais de que a atitude em relação à Matemática não é dimensão trabalhada nos cursos de formação. Há razões para supor que uma atitude positiva em relação à Matemática pode não estar sendo desenvolvida na formação inicial do professor, e tampouco pode ser inferida a partir das ações que professores manifestam em cursos de formação continuada. Este é, assim, um problema a investigar na medida em que a ausência de uma atitude positiva em relação à Matemática pode acarretar conseqüências desfavoráveis à formação do professor e ao exercício da docência.

A argumentação recém apresentada aponta os motivos que levaram à formulação da seguinte hipótese: as atitudes dos professores em formação, bem como dos professores em exercício, são negativas em relação à Matemática. Para direcionar o estudo, a hipótese acima foi especificada pelas seguintes questões: (a) professores em formação e professores em exercício apresentam diferenças em suas atitudes em relação à Matemática? (b) há diferenças, nas atitudes em relação à Matemática, de alunos do início da licenciatura em comparação com alunos do final da licenciatura em Matemática? (c) as atitudes em relação à Matemática dos professores em exercício se modificam no transcorrer da atividade profissional?

\section{Método}

O estudo caracteriza-se com uma investigação nãoexperimental (modelo ex post facto), pois não foi necessário "manipular variáveis ou designar participantes ou condições aleatoriamente” (Kerlinger, 1980, p. 130). A investigação foi, portanto, essencialmente comparativa ex post facto: comparouse a presença do fenômeno (atitude em relação à Matemática) em grupos diferentes, compostos de participantes voluntários de instituições escolares escolhidas por conveniência.

Os dados fornecidos pelos participantes sobre o fenômeno atitude negativa em relação à Matemática (variável medida) foram obtidos em circunstâncias in natura; ou seja, obtidos diretamente dos participantes (localizados no seu ambiente de trabalho ou de estudo), com cada um deles naturalmente designado a um grupo amostral, conforme valores, previamente definidos da variável examinada: formação de professores (variável atribuída). Dois valores foram definidos para essa variável: formação em curso em dois momentos desta formação (alunos de início e fim da licenciatura) e formação existente, em dois momentos da carreira (professores do início e fim da carreira).

Ao comparar a presença e o tipo de atitude (supostamente negativa) em relação à Matemática, de professores em diferentes momentos de seu exercício profissional e de futuros professores em diferentes momentos de sua formação, objetivou-se verificar as possíveis transformações de suas atitudes, no decorrer desses momentos, bem como identificar os componentes característicos de ordem qualitativa dessa variável.

\section{Participantes}

Foi estudada uma amostra composta por professores, participantes voluntários, de ambos os sexos que, no momento do estudo, ministravam aulas de Matemática de $5^{\underline{a}}$ a $8^{\underline{a}}$ séries do Ensino Fundamental e de $1^{\underline{a}}$ a $3^{\mathrm{a}}$ séries do Ensino Médio, em escolas públicas e privadas de grande área metropolitana. A amostra foi constituída também por estudantes que, na ocasião, freqüentavam cursos de Licenciatura em Matemática (especificamente aqueles do $1^{\circ}$ e do $4^{\circ}$ ano) em instituições de ensino superior pública e privada de duas cidades (uma de grande porte, outro de médio porte), instituições que disponibilizaram acesso ao pesquisador e conforme a aquiescência dos grupos de estudantes. A amostra foi, então, composta de 440 pessoas, agrupadas conforme disposto na Tabela 1.

Tabela 1

Participantes do estudo $(N=440)$, separados por grupos e sua quantidade.

\begin{tabular}{clr}
\hline Grupos & \multicolumn{1}{c}{ Integrantes } & \multicolumn{1}{c}{$n$} \\
\hline 1 & Alunos do início da Licenciatura & 185 \\
2 & $\begin{array}{l}\text { Alunos do final da Licenciatura } \\
3\end{array}$ & $\begin{array}{l}\text { Professores com 1 a 10 anos de } \\
\text { experiência }\end{array}$ \\
& $\begin{array}{l}\text { Professores com mais de 10 anos de } \\
\text { experiência }\end{array}$ & 156 \\
\hline
\end{tabular}

O resultado obtido por meio de itens do questionário permitiu assim caracterizar os participantes deste estudo: a maior parte é do sexo feminino; pertence à faixa etária compreendida entre 21 e 30 anos; graduou-se (ou estava se graduando na ocasião) em instituição de ensino superior pública; estudou (ou estudava na ocasião) no período noturno; fez (ou estava fazendo) licenciatura plena em Matemática e encontram (ou acreditam que encontrarão) dificuldade para ensinar Matemática.

\section{Procedimentos e instrumentos}

A coleta de dados ocorreu em duas fases. Na primeira, foram coletados dados de todos os participantes $(N=440)$ por meio de: (a) autobiografia, cujo título - "Eu e a Matemática" convidava o participante a discorrer livremente em uma página sobre seus vínculos com esse campo do conhecimento; (b) questionário, destinado à caracterização dos participantes de cada grupo amostral (em gênero, faixa etária, formação escolar, experiência profissional, por exemplo) e composto de questões de múltipla escolha e de questões abertas; e (c) escala de atitudes em relação à Matemática, de tipo Likert (1932), em que as respostas emitidas a cada item variam de plena concordância até uma total discordância.

Neste estudo utilizou-se uma escala tipo Likert, em que o participante deve emitir uma resposta a cada um dos itens que compõe a escala. As respostas variam de uma plena concordância 
até uma plena discordância, passando por um ponto neutro. Cada item desse tipo de escala está associado a valores numéricos que variam de um a cinco. A avaliação emitida pelo participante, em relação a certo objeto atitudinal, é calculada pela soma de suas respostas a todos os itens. Estes valores são adicionados para se obter o número de pontos para cada indivíduo e o somatório total dos pontos vem a constituir o escore.

O uso desse tipo de escala somatória tem sido muito difundido com o objetivo de medir atitudes do participante em relação ao objeto da atitude. Podem ser atribuídas muitas vantagens à aplicação desse tipo de escala. Por exemplo: maior facilidade em sua elaboração e construção; maior amplitude de respostas para cada um dos itens e, por ser mais homogênea, maior probabilidade de que a atitude esteja sendo medida.

A escala de atitudes em relação à Matemática utilizada neste estudo foi adaptada e validada por Brito (1998), e traz a seguinte inovação: retirou-se o ponto neutro, pois ele poderia levar o indivíduo a ficar indeciso e, conseqüentemente, a não emitir opinião. Com a retirada do ponto neutro, essa escala passa a apresentar quatro possibilidades de escolha, o que impele o participante a escolher uma das seguintes alternativas em cada item, dispostas na ordem que se segue: concordo totalmente, concordo, discordo e discordo totalmente. Em outro estudo a autora acima citada justifica a retirada do ponto neutro ao afirmar que "quando o indivíduo, muitas vezes, não se decide por uma alternativa isso revela muito mais a inércia do participante para efetuar a escolha que propriamente a incapacidade de expressar uma opinião a respeito de um determinado tema” (Brito, 1996, p. 191).

Este instrumento de medida das atitudes é reconhecido pela maioria dos pesquisadores que se dedicam a esse tema. Isso acontece de fato, pois "os itens da escala cobrem principalmente as razões pelas quais as pessoas possam demonstrar se gostam ou não de matemática” (Brito \& Gonçalez, 1996, p. 55).

No presente estudo, o uso deste tipo de escala permitiu mensurar a atitude dos futuros professores e dos professores em exercício em relação à Matemática. A escolha deste instrumento foi imprescindível para a realização do estudo, pois possibilitou a identificação dos graus de aceitação ou rejeição dos participantes em relação à Matemática.

Os três instrumentos de coleta de dados explicitados acima (autobiografia, questionário e escala de atitudes) foram aplicados, nesta ordem, pelo próprio pesquisador. Nem sempre os participantes estavam todos juntos, tendo sido encontrados em momentos e ambientes diferenciados.

Na segunda fase da coleta de dados foi empregada uma entrevista semi-estruturada, feita apenas com alguns dos participantes, em função do escore obtido na escala de atitudes: dentre os 440 participantes foram entrevistados os cinco que obtiveram os mais baixos escores na escala, logo, com atitudes as mais negativas; e também os cinco que tiveram escores mais altos, logo, com atitudes as mais positivas.

A intenção de entrevistar esses dez participantes foi verificar se os resultados obtidos nas entrevistas correspondiam aos resultados apresentados, por eles, na escala de atitudes.

As entrevistas foram realizadas pelo primeiro autor. Os 10 participantes foram entrevistados individualmente, em ambientes diferenciados. Ao realizar as entrevistas, o pesquisador procurou incentivar o respondente a falar abertamente sobre suas relações com a Matemática.

Com a intenção de averiguar se os depoimentos pessoais correspondiam às tendências reveladas pela escala de atitudes, o pesquisador, ao formular as perguntas, centrou sua atenção nos três domínios que caracterizam as atitudes: afetivo sentimentos com relação ao objeto (atração-repulsão, emoções manifestadas por sentimentos positivos ou negativos em relação à Matemática); cognitivo - conhecimento sobre o objeto (aquilo que o participante conhece sobre a Matemática; que diz respeito às suas percepções sobre a Matemática); conativo predisposição para agir de certa maneira em relação ao objeto (disposição para reagir diante da Matemática; apreciar ou não apreciar a Matemática de acordo com suas experiências).

As entrevistas foram registrados por meio de gravação direta, em áudio, ocorrendo também anotações do pesquisador, durante ou depois da entrevista.

\section{Análise dos dados}

A maior parte das questões do questionário, as de múltipla escolha, pediu respostas de natureza quantitativa, as quais foram estatisticamente analisadas. Também às medidas de atitudes obtidas por meio da escala foi dado tratamento estatístico para, na comparação entre grupos amostrais, examinar-se o significado das tendências encontradas para o teste da sustentabilidade da hipótese. Em ambos os casos, para o referido tratamento estatístico foi utilizado o programa SPSS (Statistical Package for the Social Sciences).

Os dados fornecidos pelas autobiografias e também pelas questões abertas do questionário e da escala de atitude, de natureza qualitativa, foram analisados mediante o programa ALCESTE (Analyse Lexicale par Contexte d'un Ensemble de Segments de Texte). O uso deste recurso tecnológico permitiu identificar padrões, tendências e motivos de aceitação ou rejeição à Matemática.

Para o exame da hipótese central deste estudo recorreu-se à análise de variância (ANOVA) dada a necessidade de verificar se as diferenças entre as médias, obtidas pelos participantes pertencentes aos quatro grupos (compostos conforme formação em curso e formação existente) eram significativas ou não. Para se verificar a consistência da hipótese foi considerado significativo o valor da probabilidade como inferior ou igual a 0,05 .

Com a intenção de tornar explícito o conteúdo das mensagens emitidas pelos participantes nas entrevistas, recorreuse à análise de conteúdo (Bardin, 1977; Duarte, 2004) que se apresenta como um conjunto de técnicas que permite conhecer o que está por trás das palavras.

\section{Resultados}

Para atender ao objetivo do estudo foram adotadas análises de natureza qualitativa e quantitativa. Esta escolha permitiu identificar vários aspectos do constructo atitude em cada um dos grupos amostrais, permitindo também uma comparação 
quanto à suposta presença de atitudes negativas em relação à Matemática.

Utilizou-se a análise fatorial para o tratamento estatístico dos dados fornecidos pela escala de atitudes. Tal procedimento foi utilizado com a intenção de verificar se a escala utilizada media, efetivamente, as atitudes dos participantes em relação à Matemática.

Para avaliar a adequação da análise fatorial aos propósitos deste estudo, foram empregados dois testes estatísticos: KaiserMeyer-Olkin (KMO) e Bartlett de esfericidade. Estes testes indicam qual é o nível de confiança que se pode esperar dos dados, quando seu tratamento for realizado por meio da análise fatorial.

A medida de adequação da amostra de Kaiser-MeyerOlkin (KMO) foi igual a 0,946 indicando que a análise fatorial podia ser realizada e se mostrava adequada. O teste Bartlett de esfericidade apresentou um nível de significância igual a 0,000 indicando que as variáveis (itens que compunham a escala) estavam correlacionadas.

Tendo-se observado que a análise fatorial havia se mostrado adequada para o tratamento dos dados, e que as variáveis estavam correlacionadas, prosseguiu-se com a análise estatística da escala de atitudes. O coeficiente alfa (ou alfa de Cronbach) é uma medida freqüentemente utilizada para indicar a confiabilidade da consistência interna entre os itens da escala de atitudes. Aplicado o teste, obteve-se um alfa de 0,925, considerado satisfatório, permitindo estimar a confiabilidade da escala em relação aos dados da amostra.

Da análise estatística (ANOVA) dos resultados provenientes da medida de atitudes $(F=0,000)$, obteve-se a rejeição da hipótese (as atitudes dos professores em formação, bem como dos professores em exercício, são negativas em relação à Matemática). Verificou-se a existência de diferenças entre as médias obtidas pelos participantes pertencentes a cada um dos quatro grupos. Uma diferença significativa se mostrou na comparação entre alunos do início da licenciatura e professores em exercício.

Ainda que não fossem significativas, as outras diferenças apontaram que os alunos iniciantes do curso de licenciatura apresentavam atitudes mais negativas que os concluintes. Apontavam também professores com 1 a 10 anos de experiência com atitudes mais positivas que professores com mais tempo de trabalho, como pode ser observado no gráfico das médias dos grupos, apresentado na Figura 1.

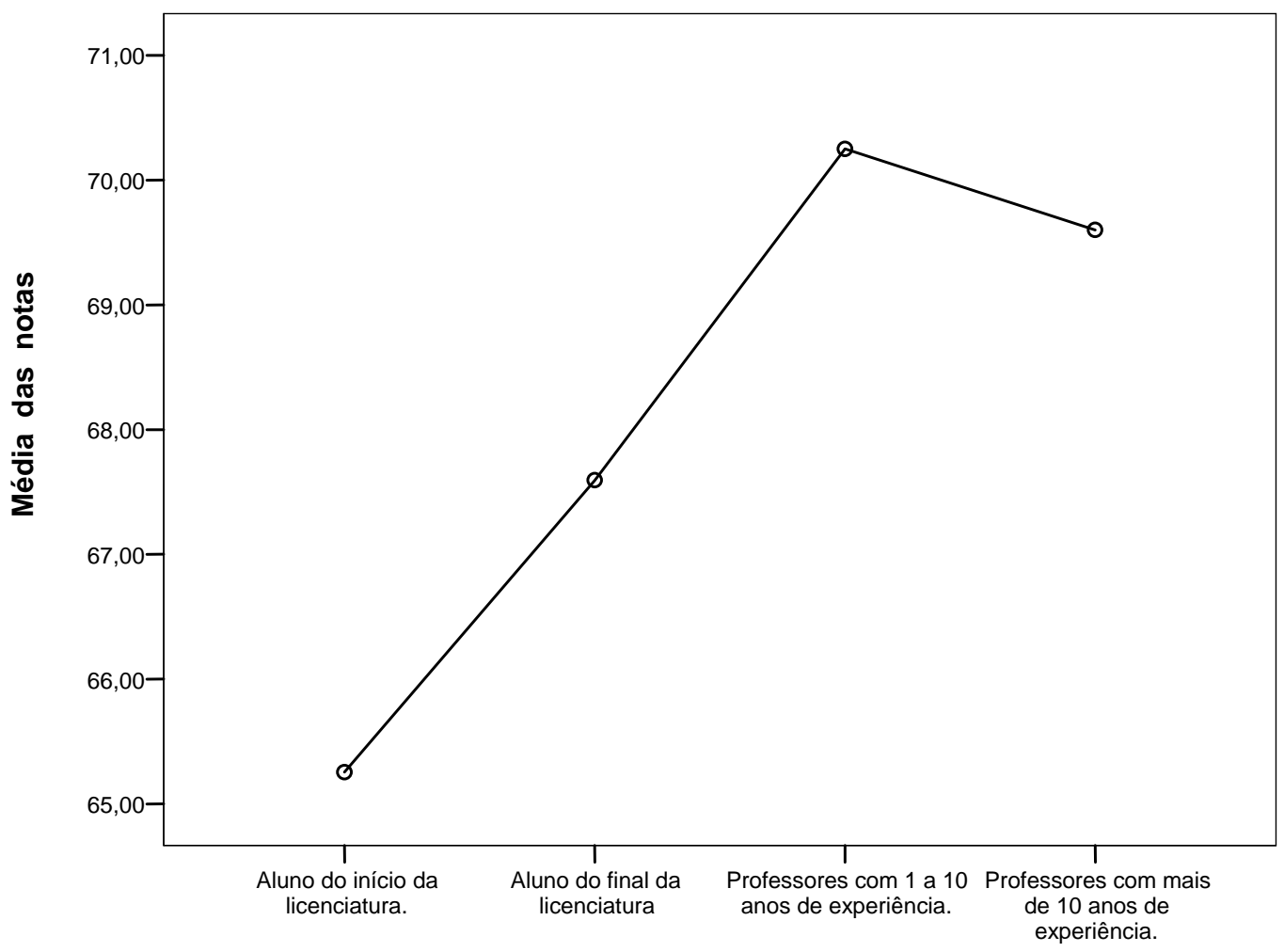

Grupos que caracterizam os sujeitos

Figura 1. Médias de acordo com os grupos.

Assim, com o presente estudo de corte transversal (dados os limites para realizar estudo longitudinal) têm-se indícios de que as atitudes em relação à Matemática se modificam durante a formação inicial e também no transcorrer da atividade profissional.
Na escala de atitudes foi incluído um item com o intuito de verificar a autopercepção de desempenho do participante como professor de Matemática. Esse item foi analisado separadamente, pois “não faz parte do modelo proposto por Aiken” (Brito, 1996, p. 285). Esse item correspondeu à afirmação "não tenho um bom 
desempenho como professor de Matemática”. Do mesmo modo que nos vinte primeiros itens da escala, os participantes tiveram que optar por uma, e somente uma, entre estas quatro alternativas de resposta: concordo totalmente, concordo, discordo e discordo totalmente. Verificou-se a distribuição das médias das notas obtidas pelos participantes utilizando-se a análise de variância (One-way). Com o intuito de averiguar quais médias eram significativamente diferentes, aplicou-se um teste post hoc (Tukey HSD). Para o nível de significância estatística estabelecido para o estudo $(0,05)$, foram observadas diferenças significativas na autopercepção dos participantes quando eles foram agrupados de acordo com a concordância (ou não) em relação à afirmação apresentada: "não tenho um bom desempenho como professor de Matemática". Aqueles que discordaram totalmente da afirmação acima apresentaram diferenças significativas em relação aos outros três agrupamentos.

Esses resultados indicaram a existência de uma relação significativa entre a autopercepção do desempenho como professor e as atitudes em relação à Matemática. Ou seja, a autopercepção de desempenho dos professores com 1 a 10 anos de experiência é menos satisfatória que a dos professores com mais de 10 anos de experiência. Há razões para supor que a autopercepção de desempenho como professor de Matemática pode se modificar em função das circunstâncias.

Para o exame do problema proposto, este trabalho adotou também uma abordagem qualitativa, com procedimentos que permitiram estabelecer relações entre variáveis, o que possibilitou a interpretação e a atribuição de significado aos dados obtidos. Por meio do programa ALCESTE foi possível tratar os conteúdos das respostas textuais então obtidas sob o ponto de vista qualitativo, para depois poder verificar sua incidência quantitativamente. Depois de se terem submetido os dados ao referido software, iniciou-se a análise dos resultados apresentados, os quais podem ser observados nas sínteses que se seguem.

Uma das questões do questionário sugeria que o participante apontasse a razão de escolha do curso superior. Foi possível presumir que uma atitude anterior positiva em relação à Matemática tenha contribuído para a escolha da licenciatura, mas as experiências vivenciadas logo no início do curso podem ter mudado esta atitude. Os resultados apresentados permitiram ajuizar que, quando do ingresso no curso de licenciatura, há mudança de atitude em relação à Matemática (de positiva para negativa). Para os iniciantes do curso, é provável que essa mudança de atitude esteja relacionada às circunstâncias em que o participante se encontra em determinado momento da vida estudantil.

Outra questão do referido questionário solicitava que o participante indicasse o fator que mais contribuía para a dificuldade encontrada ao ensinar Matemática. Os resultados indicaram que a predisposição para o exercício da docência pode se modificar com o passar do tempo. Fatores econômicos e sociais foram apontados pelos professores com mais de 10 anos de experiência como elementos que dificultam o ensino da Matemática. Contribuem para esse resultado fatores como a "falta de recursos didáticos", a "precariedade das escolas", a "marginalização dos jovens" e a "indisciplina dos alunos", os quais podem estar ligados a uma avaliação desfavorável da profissão docente, e conseqüentemente da Matemática, manifestada por esses participantes.

Solicitou-se também que o participante citasse a principal razão que o havia motivado a lecionar Matemática. Os resultados permitiram observar que as razões que levaram os professores com 1 a 10 anos de experiência a lecionar estão ligadas ao gosto, ao fascínio e à paixão que têm pela Matemática. A partir do momento em que começam a lecionar, ocorre maior interesse pela Matemática e pelo seu ensino. Outros importantes elementos compõem essa decisão, tais como: a facilidade de ensinar e o sentimento de prazer ao observar que o aluno aprende.

O tema abordado na autobiografia foi: Eu e a Matemática. Os resultados permitiram observar que os professores de 1 a 10 anos de experiência não se diferenciam dos alunos iniciantes quanto à importância da compreensão dos conceitos matemáticos. Mas os argumentos utilizados para destacar tal importância são diferentes. Os alunos iniciantes enfatizaram a necessidade da compreensão efetiva dos conceitos matemáticos e não somente a memorização e reprodução de procedimentos algorítmicos. Já os professores de 1 a 10 anos de experiência enfatizaram que a importância da compreensão está ligada à possibilidade do exercício da cidadania.

A análise dos dados obtidos nas entrevistas semi-estruturadas permitiu a identificação de traços predominantes do conjunto das falas dos cinco participantes com atitudes mais positivas e dos cinco participantes com atitudes mais negativas. A partir desses elementos foi possível traçar um perfil de participantes com atitudes as mais positivas (perfil positivo) e um perfil de participantes com atitudes as mais negativas (perfil negativo). $\mathrm{O}$ perfil vem da identificação de traços predominantes, observados no conjunto das falas que foram organizadas em eixos e subeixos temáticos.

O perfil de um participante com atitudes as mais positivas compõe-se das seguintes características predominantes:

- Bons sentimentos em relação à Matemática.

- Convicção de que a Matemática é um bem cultural.

- Predisposição para estudar e aprender Matemática.

- Ausência de dificuldades em relação à Matemática.

- Crença na importância dos conhecimentos adquiridos na licenciatura.

- Certeza de que a Matemática contribui para o desenvolvimento da forma de pensar do ser humano.

- Clareza da importância da Matemática como disciplina escolar.

- Crença em que um bom professor poderá mudar o estigma de que a Matemática é uma ciência difícil.

- Percepção de que a profissão docente não tem o reconhecimento que merece.

- Confiança em um bom desempenho no exercício da docência.

O perfil de um participante com atitudes as mais negativas contém os seguintes traços predominantes:

- Maus sentimentos em relação à Matemática.

- Aversão ao estudo e aprendizagem da Matemática.

- Dificuldades em relação à Matemática ensinada no Ensino 
Superior.

- Ceticismo em relação à importância dos conhecimentos adquiridos na licenciatura.

- Decepção em relação ao curso de licenciatura.

- Sentimento de medo em relação à Matemática provocado pelo curso de licenciatura.

- Desejo de desistir do curso de licenciatura em virtude da reprovação e da forma como a Matemática é ensinada no Ensino Superior.

- Mau desempenho enquanto estudante de licenciatura em Matemática.

- Persistência para concluir a formação docente, por mais que se apresentem grandes dificuldades para aprender Matemática.

- Falta de confiança em um bom desempenho no exercício da docência.

Tomando como referência as análises realizadas, é possível afirmar que há uma correspondência entre a direção de sentimentos, crenças e predisposições, em sentido positivo ou negativo. Pode-se falar a favor de certa congruência nos traços de cada perfil, pois, mesmo no perfil de participantes com atitudes as mais negativas, a persistência - um traço positivo - apontaria para o quanto essa característica deve ser exigida em um quadro de tantos sentimentos, crenças e predisposições desfavoráveis à Matemática.

\section{Discussão e implicações do estudo}

Os resultados da análise qualitativa de respostas às perguntas abertas (escritas no questionário, na escala de atitudes e na autobiografia) e às perguntas da entrevista oral, corroboram resultados da análise quantitativa e sugerem pistas para a explicação da mudança de atitude nos grupos amostrais. Por exemplo, o perfil delineado para os participantes com atitudes mais negativas e mais positivas permite interpretar a diferença de atitude entre os iniciantes do curso de licenciatura (com atitudes as mais negativas) e os professores com um a dez anos de experiência (com atitudes as mais positivas), pois se pode supor certa congruência entre os traços de cada perfil e as atitudes em relação à Matemática para os respectivos grupos.

Os resultados obtidos permitem ajuizar que, quando do ingresso no curso de licenciatura, há mudança de atitude em relação à Matemática (de positiva para negativa). Na passagem compreendida entre a conclusão do curso e o ingresso no mercado de trabalho também há mudança de atitude (de negativa para positiva).

É possível presumir que uma anterior atitude positiva em relação à Matemática contribua para a escolha da licenciatura, mas as experiências vivenciadas logo no início do curso podem mudar esta atitude. Os traços característicos do perfil para os participantes com atitudes as mais negativas revelam sinais de que esses participantes passam a avaliar desfavoravelmente o objeto da atitude, o que corresponde a marcas ligadas a uma atitude negativa em relação à Matemática. Assim, para os iniciantes do curso, é provável que essa mudança de atitude (de positiva para negativa) esteja relacionada às circunstâncias em que o participante se encontra em determinado momento da vida estudantil.

Na passagem compreendida entre a conclusão do curso e o ingresso no mercado de trabalho, foi possível constatar a existência de uma relação significativa entre a autopercepção do desempenho como professor e as atitudes em relação à Matemática. Os professores com um a dez anos de experiência apresentam atitudes mais positivas, que correspondem a uma boa autopercepção de desempenho como professor de Matemática. O mesmo não aconteceu com os alunos do final da licenciatura.

Por outro lado, um dos traços revelados no perfil dos participantes com atitudes as mais negativas foi a persistência para concluir o curso. Assim, mesmo tendo apresentado grandes dificuldades durante o curso (provavelmente de aprendizagem), é possível que a conclusão da licenciatura possa representar uma conquista e ao mesmo tempo um alívio. A possibilidade de entrada no mercado de trabalho, em função de empenho em concluir o curso, pode se apresentar como um fator importante para a mudança de atitude (de negativa para positiva).

Ao que tudo indica, a condição em que a pessoa se encontra no final da licenciatura e no início da carreira, associada à sua autopercepção de desempenho, denota que a mudança de atitude (de negativa para positiva) está relacionada às particularidades de um determinado momento da vida estudantil ou profissional.

As razões de escolha do curso superior, os fatores que dificultam o ensino da Matemática, as razões que levam a lecionar Matemática e os relatos autobiográficos que expõem as relações entre o participante e a Matemática revelam a possibilidade de haver alguma correspondência entre as atitudes para com a Matemática e as circunstâncias em que a pessoa se encontra em determinado momento da vida estudantil ou profissional. Nesse contexto há razões para supor que a atitude em relação à Matemática se modifica em decorrência das circunstâncias.

Assim, recomendações são endereçadas aos responsáveis pelo desenvolvimento dos cursos de licenciatura em Matemática. Eles devem dispensar mais atenção às situações de ensino propostas aos futuros professores. Já no início do curso, elas devem estimular o entusiasmo pela Matemática e também o desejo de ensinar. Situações contrárias a essas podem contribuir para a formação de uma atitude negativa em relação à Matemática.

O futuro professor deve adquirir conhecimentos novos, estudar como os alunos aprendem Matemática, analisar os problemas relacionados ao ensino desta disciplina e aprender a usar novos materiais e recursos tecnológicos. Dependendo do tipo de encaminhamento dado a essas questões, na formação inicial, elas poderão se apresentar como possibilidades para o desenvolvimento de uma tendência a avaliar favoravelmente a Matemática.

Considerando que as atitudes acerca da Matemática podem estar relacionadas com o tipo de experiência vivenciada pelos futuros professores nos cursos de licenciatura, notadamente aquelas relacionadas ao desempenho apresentado nas disciplinas ofertadas logo no início desses cursos (resultado fortemente apontado neste estudo), deve haver uma preocupação com o modo como os professores universitários ensinam e como os estudantes de licenciatura aprendem. 
Assim, no que se refere ao planejamento dos programas das disciplinas ofertadas nos cursos de licenciatura, deve-se levar em conta a necessidade da definição de critérios para a formação de professores. Os cursos que preparam professores de Matemática devem estar atentos para os seguintes aspectos:

- levar em consideração os sentimentos que os estudantes experimentam em relação ao objeto da atitude (a Matemática per se), pois eles podem conduzir os estudantes a avaliar o objeto da atitude de maneira favorável ou desfavorável;

- observar as associações que os estudantes estabelecem entre o que já conhecem e o objeto da atitude, pois elas devem favorecer a demonstração do seu conhecimento sobre a Matemática e sobre a importância do ensino desta ciência;

- estimular o desenvolvimento de situações de ensino e de avaliação da aprendizagem, por meio das quais os estudantes apresentem predisposições para apreciar a Matemática enquanto ciência e se empenhem em seu estudo.

Tais recomendações são importantes, pois os estudantes não devem somente adquirir conhecimentos, mas também, nesse mesmo processo, devem formar atitudes positivas em relação à Matemática, as quais podem contribuir para que os futuros professores possam compreender as complexas situações que envolvem tanto o ensino quanto a aprendizagem.

Certamente um dos aspectos que poderia contribuir nessa direção seria o fortalecimento da articulação entre teoria (o que ensinar) e prática (como ensinar). No decorrer da formação inicial, o estímulo à pesquisa individual e coletiva, bem como a prática de ensino e o estágio supervisionado podem trazer tal contribuição. Tanto na formação inicial quanto na formação continuada, deve-se valorizar a idéia de que os professores podem aprender de diversas maneiras: a partir de sua própria prática, com seus colegas, com seus alunos, pelo uso de materiais didáticos, por meio de estudos teóricos, pelo contato com profissionais mais experientes em palestras e cursos de formação continuada, etc.

Na formação inicial, é fundamental que o futuro professor tenha um sólido conhecimento matemático, não na forma de estoque armazenado, mas na forma de domínio conceitual. Assim, ele poderá (a partir da utilização de uma metodologia de ensino adequada) desenvolver atitudes positivas para com a Matemática, a fim de torná-lo capaz de aproveitar ao máximo a riqueza das possibilidades de conhecimento propiciadas pela escola. Deste modo, é possível que ele tenha melhores condições de ajudar seus futuros alunos a desenvolverem uma avaliação favorável da Matemática e, conseqüentemente, uma atitude positiva diante dessa ciência.

\section{Agradecimentos}

Os autores agradecem o apoio financeiro da CAPES.

\section{Referências}

Aiken, L. R., \& Dreger, R. M. (1961). The effect of attitudes on performance in mathematics. Journal of Educational Psychology, 52(1), 19-24.

Bardin, L. (1977). Análise de conteúdo (L. A. Reto e A. Pinheiro, Trad.). Lisboa: Edições 70.

Bogardus, E. S. (1925). Measuring social distance. Journal of Applied Sociology, 9, 299-308.

Brito, M. R. F. de (1996). Um estudo sobre as atitudes em relação à Matemática em estudantes de $1^{\circ}$ e $2^{\underline{o}}$ graus. Tese de livre docência não-publicada, Universidade Estadual de Campinas, Campinas.

Brito, M. R. F. de (1998). Adaptação e validação de uma escala de atitudes em relação à Matemática. Zetetiké, 6(9), 109-162.

Brito, M. R. F. de, \& Gonçalez, M. (1996). Atitudes (des)favoráveis com relação à Matemática. Zetetiké, 4(6), 45-63.

Duarte, R. (2004). Entrevistas em pesquisas qualitativas. Educar em Revista, 24, 213-225.

Eagly, A. H., \& Chaiken, S. (1993). The psychology of attitudes. Belmont, California: Wadsworth Group/Thomson Learning.

Faria, P. C. de (1996). A formação do professor de matemática: problemas e perspectivas. Dissertação de mestrado não-publicada, Universidade Federal do Paraná, Curitiba.

Faria, P. C. de (2003). A formação do professor de matemática [Resumo]. In Comitê Interamericano de Educação Matemática (Org.), XI Conferência Interamericana de Educação Matemática. Resumos (pp. 13-17). Blumenau: Autor.

García, C. (1999). Formação de professores: para uma mudança educativa. Porto: Porto.

Giordano, G. (1991). Altering attitudes toward Mathematics. Principal, 70(3), 41-43.

Gonçalez, M. H. C. de C., \& Brito, M. R. F de (2001). A aprendizagem de atitudes positivas em relação à matemática. In M. R. F. de Brito (Org.), Psicologia da educação matemática: teoria e pesquisa (pp. 221-233). Florianópolis: Insular.

Guskey, T. R. (1986). Staff development and the process of teacher change. Educational Researcher, 15(5), 5-12.

Guttman, L. (1944). A basis for scaling qualitative data. American Sociological Review, 9(2), 139-150.

Karp, K. S. (1991). Elementary school teachers' attitudes toward mathematics: The impact on students' autonomous learning skills. School Science and Mathematics, 91(6), 265-270.

Kerlinger, F. N. (1980). Metodologia da pesquisa em ciências sociais: um tratamento conceitual. São Paulo: EPU/EDUSP.

Larson, C. N. (1983). Techniques for developing positive attitudes in preservice teachers. Arithmetic Teacher, 31(2), 8-9.

Likert, R. (1932). A technique for the measurement of attitudes. Archives of Psychology, 22(140), 1-55.

Osgood, C. E., Suci, G., \& Tannenbaum, P.H. (1957). The measurement of meaning. Urbana, Illinois: University of Illinois Press.

Sallán, J. (1990). Las actitudes en educación: un estudio sobre educación matemática. Barcelona: Boixareu Universitária.

Thurstone, L. L. (1928). Attitudes can be measured. American Journal of Sociology, 33, 529-554.

Trillo, F. (2000). As atitudes dos estudantes: um indicador da qualidade universitária. In F. Trillo (Org.), Atitudes e valores no ensino (pp. 215-258). Lisboa: Instituto Piaget. 
1. Este artigo apresenta resultados da tese de Doutorado em Educação defendida pelo primeiro autor, sob a orientação da segunda autora e com a valiosa colaboração da terceira autora, no Programa de Pós-Graduação em Educação da Universidade Federal do Paraná.

Paulo Cézar de Faria, doutor em Educação Matemática pela Universidade Federal do Paraná, é professor adjunto no Departamento de Matemática, da Universidade Federal do Rio Grande do Norte. Endereço para correspondência: Rua Dona Maria Câmara, 1988 (Capim Macio); Natal, RN; CEP: 59082-430, Telefones: (84) 3082-0142. Fax: (84) 3215-3819. E-mail: paulocezar@ccet.ufrn.br ou pfaria88@gmail.com Maria Lucia Faria Moro, doutora em Psicologia da Educaçao pela Pontifícia Universidade Católica de São Paulo, é professora colaboradora senior no Programa de Pós-Graduação em Educação da Universidade Federal do Paraná. E-mail: mlfmoro@sul.com.br

Marcia Regina Ferreira de Brito, doutora em Psicologia da Educação pela Pontifícia Universidade Católica de São Paulo, é professora titular no Departamento de Psicologia Educacional da Universidade Estadual de Campinas. E-mail: mbrito@unicamp.br 